\title{
Municipal Training Needs and Personnel Practices: Implicalions for Program Planning and Policy Making
}

\author{
SAMUEL A. KIRKPATRICK \\ University of Oklahoma
}

\author{
DAVID R. MORGAN \\ University of Oklahoma
}

\author{
WILLIAM LYONS \\ University of Oklahoma
}

While one might debate Pope's famous maxim that the government is best that is administered best, there would be little argument that governmental effectiveness is significantly influenced by the quality of its personnel. In recent years there has been a growing awareness of the importance of attracting well-qualified, competent people into local public service and insuring that they are provided not only with the resources but the know-how and training necessary to perform well. ${ }^{1}$ Social scientists have also become increasingly interested in measuring and evaluating local public services in hopes of discovering factors that might be related to more effective service production. Preliminary results from certain studies have already begun to challenge long-standing assumptions about such things as the relationship between expenditures and service levels ${ }^{2}$ and between resource levels and policy effectiveness. ${ }^{3}$ Clearly these findings

Samuel A. Kirkpatrick (Ph. D., Pennsylvania State University) is Director of the Bureau of Government Research and Associate Professor of Political Science at the University of Oklahoma. $\mathrm{He}$ is the author of a variety of books and articles on urban affairs, research methodology, social psychology and politics, mass attitudes and electoral behavior. With David R. Morgan, he is coauthor of Urban Political Analysis: A Systems Approach (Free Press, 1972).

David R. Morgan (Ph. D., University of Oklahoma) is Associate Director of the Bureau of Government Research and Associate Professor of Political Science at the University of Oklahoma. He is the coauthor of Urban Political Analysis and is the author of several articles and monographs on urban affairs, urban management and metropolitan integration. He has also been engaged in teaching and research in the area of public policy analysis.

William Lyons (M. A., University of Oklahoma) is currently a Ph. D. candidate at the University of Oklahoma and Research Assistant in the Bureau of Government Research. He has taught in the area of American politics and research methodology and is engaged in research in urban affairs, public policy analysis, and electoral behavior.

\footnotetext{
1Municipal Manpower Commission, Governmental Manpower for Tomorrow's Cities (New York: McGraw-Hill, 1962).

2Ira Sharkansky, "Governmental Expenditures and Public Services in the American States," 61 American Political Science Review, (1967), pp. 1066-77.

3 E. Terrence Jones, "Evaluating Everyday Policies: Police Activity and Crime Incidence," 8 Urban Affairs Quarterly, (1973), pp. 267-79.
} 
emphasize that the quality of public service is dependent on much more than increased funds and more manpower. The way in which services are rendered would also appear to be equally crucial, at least after certain minimal levels of resources have been provided. Yet, previously little systematic attention has been devoted to exploring just how the quality of local public services might be improved. "Hire more people, buy more equipment, spend more money," has often been the stock answer. It is increasingly obvious, however, that cities must look at internal operations and practices for clues to improving the quality of public services. While a number of such internal processes might be examined, it would certainly seem appropriate to more closely scrutinize those activities by which a city recruits, selects and trains its employees. Although documenting just how personnel and training practices might directly result in higher levels of service would not be easy, it is difficult to argue that these activities are unimportant. In fact, the need for improving utilization and management of local government personnel has now been officially recognized by the Federal government with the passage in 1970 of the Intergovernmental Personnel Act. Despite this new concern, our knowledge is quite meager about what city governments currently have in the way of personnel and training policies and practices. We do not really know what now exists, what the needs are, and how these needs might be most effectively met. This report deals with the efforts of one state to provide answers to some of these questions.

As a first step in gathering the information necessary to make intelligent decisions concerning the use of IPA funds, the Office of Community Affairs and Planning in Oklahoma commissioned the authors to undertake a comprehensive personnel and training survey of all city governments in the State of 2,500 population or over in the summer of $1972(\mathrm{~N}=72) .^{4}$ Data, which were gathered by mailed questionnaires and personal interviews in the two largest cities, were supplied primarily by city managers where such were available and city clerks and department heads in noncouncil-manager cities. Among other things, we were especially interested in determining the particular functional areas where training needs were greatest and also to learn what characteristics of a government might contribute to a greater interest in training. In addition we wanted to know what kinds of personnel policies and practices existed in Oklahoma communities and whether these might also be related to certain city character-

4The study was partially funded by a grant from the United States Civil Service Commission under the provisions of the Intergovernmental Personnel Act. However, the Commission is not responsible for nor does it necessarily subscribe to any of the conclusions from the data analysis. 
istics and perhaps to interest in training as well. While the study was confined to one State with only two cities of over 100,000 population, the findings here should have at least some application to small and medium sized cities in the midwest and south and southwest.

\section{Levels of Training Interest}

City respondents were asked to indicate their degree of interest in 21 different training course possibilities, some of which were currently being offered to cities in the State while others were hypothetical courses that might be considered of potential interest. Training course possibilities were to be marked as to high, middle, or low priority or no interest. In addition, the respondents were asked to choose their three top training preferences. A no response on any given training category was treated as no interest. Thus it was possible to calculate a mean score for each training course possibility that would range from 1 to 5 (with high values indicating greater interest or need). Table 1 reflects the mean score for each of these 21 training course possibilities.

Table 1

Mean Score for City Training Needs and Preferences*

Preference Area

Mean

Water and Sewage Plant Operator Training

3.22

Police Specialized Skills Training

3.15

Grant Sources and Application Procedures

3.14

Police Human Relations Training

3.10

Police Recruit Training

3.10

Middle Management (Supervisory) Training 3.03

Fire Specialized Skills Training

2.99

Basic Management Principles (All Departments) 2.96

Building Inspection Code Enforcement $\quad 2.86$

Solid Waste Disposal Training $\quad 2.82$

Clerk, Treasurer, Finance Officer Training 2.81

Labor Relations Training $\quad \mathbf{2 . 7 9}$

Personnel Administration Training $\quad 2.79$

Electrical Inspection Code Enforcement 2.74

Plumbing Inspection Code Enforcement

Fire Recruit Training $\quad 2.69$

City Planning Short Courses $\quad 2.67$

Occupational Safety and Health $\quad 2.56$

General Clerical and Office Training $\quad 2.19$

Heavy Equipment Operator Training $\quad 2.17$

Vehicle Mechanic Training 2.11

*Higher scores indicate greater need or preference. 
There are several interesting patterns to note on the basis of the above distribution. Among the high scores we find some traditional course areas where needs still exist or could be expanded, i. e., water and sewer training and police recruit training. Yet there is also a clear expression of need for some training in relatively new areas, i. e., grant sources and applications, police human relations, and management and supervision training. A need for extension of existing specialized training was also expressed in the police and fire areas. We were somewhat surprised to see the moderate level of need for labor relations training - an area that is often articulated as a need by local government experts and one that is in vogue given trends toward employee unionization. This factor may obviously be a function of city size and the existence of unionization in a particular city.

In addition to determining the degree of interest among cities in each of a series of possible training areas, a composite training interest score for each city was devised. This was done by summing the scores for each of the 21 individual need areas resulting in a theoretical range for each city from a low of 21 (21 "one" scores) to a high of 87 (three "five" scores for highest interest plus 18 "four" scores). By constructing this training interest index for each city, it becomes possible to examine some of the factors or conditions associated with greater interest in training. In effect, this analysis seeks to distinguish between high and low interest cities and to develop a profile of those communities with greater overall interest in training that will assist policy makers in planning programs to meet city needs with a minimum of wasted resources.

If high training interest cities are identified, their attitudes toward certain factors that might affect training activities would obviously be of interest. Respondents in the study were asked to indicate the degree of importance (from 1 to 3 , with low scores indicating greater importance) assigned to each of the following items that might influence the success of a training program: close training sites, less expensive training, support from elected office holders, more training time, greater interest from department heads, more money, and more specialized training. Table 2 reveals the relationship between these various factors and the overall interest in training index, using the gamma statistic that varies from +1 to -1 .

Although none of the relationships might be considered as particularly strong, one does stand out - the importance of support from elected officials. This means that cities most interested in training feel 
Table 2

Correlations (Gamma) Between Level of Overall Training Interest and Importance of Various Factors Related to Training

\begin{tabular}{lc}
\hline \multicolumn{1}{c}{ Factors } & Gamma* \\
\hline Training Sites Close & -.01 \\
Less Expensive Training & -.08 \\
Support from Officials & -.30 \\
More Training Time & -.12 \\
Department Head Interest & -.19 \\
More Money & -.12 \\
More Specialized Training & .04 \\
\hline
\end{tabular}

*The negative gamma coefficients reflect the coding procedure utilized: high interest was scored with higher numerical values and greater importance was coded with lower numerical values.

that support for that effort on the part of elected office holders is vital. 5

In addition to knowing something about those factors deemed important to training success, for purposes of creating a more complete picture of cities with high interest in training we also need to know something about the characteristics of the cities themselves. In particular, are such things as size of city, the magnitude of its budget, and the degree of sophistication of its personnel system related to levels of training interest? While one might expect higher budget cities to evidence higher overall training interest, few distinguishing patterns emerge. The correlation coefficient $(\mathrm{r})$ between budget size and overall training interest is only -.06, indicating that there is virtually no relationship between the two items. When the 21 individual training areas are compared with budget size, most relate at a level of .20 or less, with three notable exceptions: basic management (.27), middle management (.31), and labor relations (.27). This means that there is a tendency for larger budget cities to be more interested in training courses of this type.

When size of city is compared with level of training interest, similar results are found. Larger cities are not distinguished by their increased overall interest in training as indicated by a low correlation of .16 between city size and the overall training interest index. However, several notable exceptions emerge when the 21 training possibilities are examined separately. As city size increases, there is a correspondingly greater interest in the following training course areas (correlation coefficient with size shown

5For a discussion of similar sets of constraints see Charles T. Henry, "Overcoming the Obstacles to Local Government Training Programs," 4 Midwest Review of Public Administration, (1970), pp. 25-30. 
in parentheses): basic management (.43), middle management (.51), and labor relations $(.49)$. These were the same areas of interest that related to budget size and indicate, as expected, that there is a relationship between budgetary commitment and city size (.46).

Finally, it was thought that certain personnel characteristics among cities might be related to interest in training. If decision makers wish to encourage an environment conducive to heightened interest in training, it becomes useful to know whether changes in personnel system characteristics might facilitate this goal. Clearly, one factor may not precede the other, i. e., we cannot speak of a cause and effect relationship, but knowing that two factors may occur together is itself important.

In order to assess the relationship between training interest and the personnel environment, 13 personnel characteristics were cross-tabulated with a three-level division of the training interest index (low, medium, high). A summary of these relationships (gamma) between the existence/ non-existence of personnel characteristics and levels of interest is shown in Table 3. Table 3 indicates a relatively uniform tendency for those characteristics listed to be associated with higher training interest, which is important in itself. The variation in magnitude, however, suggests that

\section{Table 3}

Summary Table of Relationships (Gamma) Between the Presence of Selected Personnel Characteristics and Level of Interest in Training

\begin{tabular}{lr}
\hline \multicolumn{1}{c}{ Characteristics } & Gamma \\
\hline Formal Merit System & -.18 \\
Written Personnel Plan & -.29 \\
Position Classification Plan & -.37 \\
Written Grievance Procedures & -.60 \\
Written Examination for Employment & -.01 \\
Written Examination for Promotion & -.41 \\
Written Performance Evaluations & -.23 \\
Employment Probationary Period & -.42 \\
Health and Hospital Plan & -.28 \\
Life Insurance Plan & -.39 \\
Employee Retirement System & -.53 \\
Employee Retirement Contribution & -.20 \\
Employees Unionized & -.23 \\
\hline
\end{tabular}

* Negative coefficients result from the particular coding procedures used in the study. Since all gammas are negative, they indicate a tendency for "yes" responses on the characteristics to be associated with higher levels of interest, and vice versa. 
some personnel features are more closely affiliated with training interest than are others. Thus, those cities with employee grievance procedures, an employee retirement system, a position-classification plan, written examinations for promotion, and an employee probationary period are most likely to evidence higher levels of training interest, and vice versa.

In summary, the size of city and the magnitude of the budget are not closely related to an overall heightened interest in training, with certain exceptions among particular training course areas. However, those cities that do show greater concern for training are those which have relatively well developed personnel systems. Thus, it can be said that an interest in training does coincide with more advanced personnel practices, although which comes first cannot be determined from this analysis.

\section{Personnel Policies}

In order to more accurately assess the relationship between specific sets of training needs on the one hand, and city characteristics and personnel policies on the other, we undertook further analysis to uncover hidden effects in a city's overall level of training interest. This effort raises a number of questions of both academic and practical significance. What is the relationship between personnel practices and city size? Is it possible to consider personnel practices as a single group or are such policies relatively unrelated? To what extent are specific training needs related to each other and are there basic sets of needs which go together? What is the nature of the relationships among needs, personnel policies and city characteristics?

The above questions are related to a larger issue of interest to academics and practitioners. Implicitly, perhaps, both groups seem to share a working hypothesis that modern up-to-date personnel practices are conducive to developing a more professionally-oriented city administration. While this relationship has not been fully established, there are logical reasons to expect that cities with sophisticated personnel systems are more likely, for example, to be interested in training, in establishing high employment entrance standards, and perhaps less oriented toward the local job market in recruitment. If this is so, policy makers may find it useful to know the extent to which personnel practices and certain city characteristics may be related to interest in training so that more intelligent plans for meeting training needs can be devised.

Most national studies have found quite logically and convincingly that merit-oriented and employee benefit policies are a direct function of 
city size. ${ }^{6}$ There are compelling reasons for such a pattern to exist: larger cities have more complex bureaucracies, more employees, and a more diversified set of needs to meet. In addition, larger cities have a more competitive environment for skilled personnel, and the standards set by the private sector in larger industries are more immediately apparent. Table 4 presents evidence to support the relationship between city size and

Table 4

Correlations (Tau c) Between City Size and Personnel Practices

\begin{tabular}{lc}
\hline \hline \multicolumn{1}{c}{ Characteristics } & Tau c* \\
\hline Formal merit system & -.23 \\
Written personnel plan & -.42 \\
Position classification plan & -.52 \\
Written grievance procedure & -.54 \\
Written exams for employment & -.57 \\
Written exams for promotion & -.59 \\
Written performance evaluation & -.51 \\
Employee probationary period & -.21 \\
Employee pay raise basis & -.09 \\
Group health and hospital plan & -.24 \\
Employee life insurance plan & -.42 \\
Employee retirement coverage & -.24 \\
\hline
\end{tabular}

*Negative coefficients result from the coding procedures: negative gammas indicate that the presence of personnel practices are more common in larger cities.

personnel policies in Oklahoma cities (the higher the coefficient, the stronger the association). With the possible exception of the probationary period variable, the entire range of merit and employee-benefit oriented personnel characteristics are more likely to be found in larger cities. The probationary period is cited as a possible exception since the existence of such a period may be interpreted as less employee-oriented. In addition, we find that there are some policies which are more closely linked to city size. For example, position classification plans, written examinations for employment and promotion, written grievance procedures, and written performance evaluations are found particularly in larger cities.

In addition to city size, we examined the relationship between city resources as measured by its 1971.72 budget and personnel characteristics. Since the relationship between city size and budget size is not as high as some observers might expect $(\mathrm{r}=.46)$, the relationship between budget and personnel policies is less marked than the relationship between size and personnel characteristics. While the highest correlations are not above .4,

${ }^{6}$ See First National Survey of Employee Benefits for Full-Time Personnel of U. S. Municipalities (Washington, D. C.: Labor-Management Relations Service, 1973); The Municipal Year Book (Washington, D. C.: International City Management Association, 1965) pp. 203-205; Ibid., 1966, pp. 179-81; and Ibid., 1969, p. 86. 
the same pattern of effects exist, i. e., the evaluation and grievance procedures are found in larger budget cities.

It would also seem logical that certain personnel policies might exist together in clusters throughout our reporting cities. Any interrelationship of this sort would be hidden in the above analysis. Therefore, we intercorrelated (phi matrix) all personnel characteristics and subjected them to a factor analysis to isolate clusters of frequently occurring characteristics as shown in Table 5 .

Table 5

Factor Analysis (Varimax)* of Personnel Practices and Policies in Oklahoma Cities

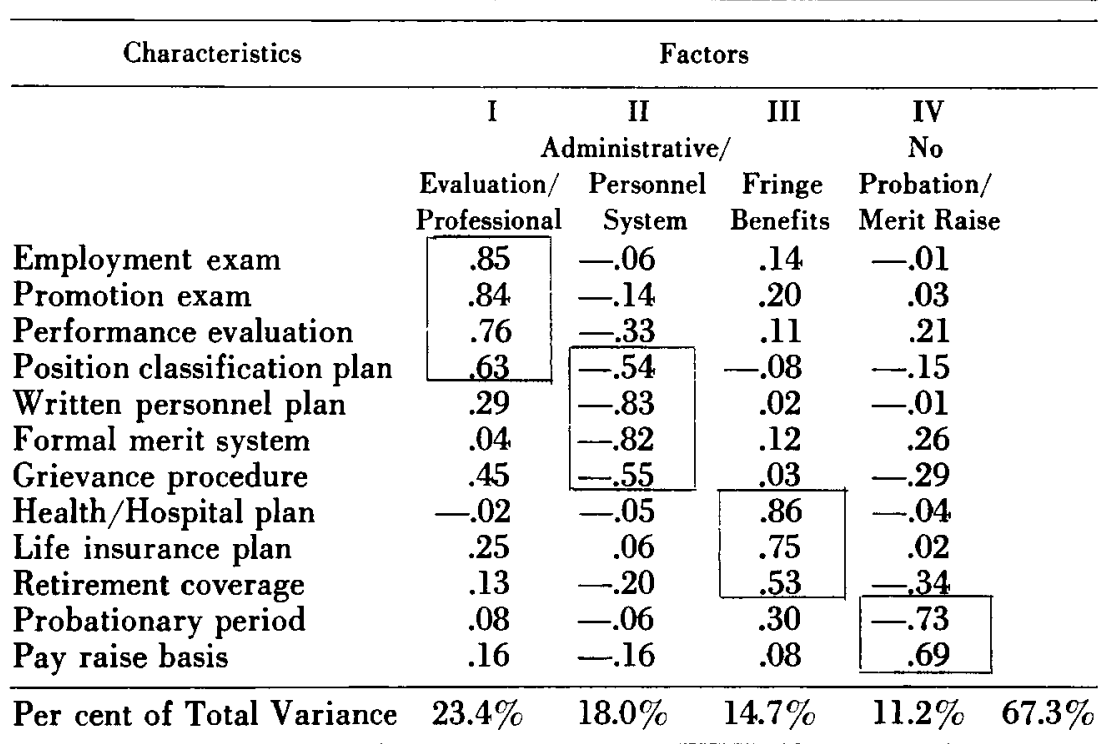

*Varimax rotation of principal components solution from a phi matrix; Kaiser's criterion for the number of factors.

The first factor which emerges appears to be an evaluation/professional dimension. It indicates that the three evaluation/examination variables are likely to occur together in Oklahoma cities. In addition, a basic component of an advanced personnel system - a position classification plan - is found in these same cities. These items therefore represent the most "professionally advanced" personnel characteristics which tend to occur together across our universe.

A second dimension is clearly an administrative/personnel system cluster where a formal merit system, written personnel plan and grievance 
procedures are found together. The position classification plan variable also has a moderate factor loading on this dimension, yet the high loading for a merit system and written personnel plan indicates that those characteristics are independent of evaluation procedures. Another independent cluster represents employee fringe benefits: health and hospital provisions, life insurance provisions and more extensive retirement coverage are more likely to cluster together and their co-occurrence is independent of other personnel characteristics. Finally, the factor analysis isolated the absence of probationary periods in cities with merit pay increases.

When each city's factor score along each of the four basic personnel policy dimensions is correlated with population and budget size, we are able to clarify earlier findings. Table 6 indicates that the closest relation. ship exists between city size and the presence of a set of evaluation and

Table 6

Correlations Between City Characteristics and Personnel Policy Dimensions

\begin{tabular}{lcr}
\hline \multicolumn{1}{c}{ Personnel Policies } & Population & Budget \\
\hline Evaluation/Professional & -.61 & -.41 \\
Administrative/Personnel & .24 & .10 \\
Fringe Benefits & -.38 & -.12 \\
No Probation/Merit Raise & .11 & .08 \\
\hline
\end{tabular}

professional policies. A moderate relationship also exists between budget size and these policies. Indeed, of all personnel policy dimensions, we are best able to predict the evaluation/professional factor from knowledge of city size or budget characteristics. Fringe benefit policies and the set of administrative/personnel policies are also moderately related to these two basic city characteristics. ${ }^{\top}$

In sum, four primary clusters of personnel policies emerge for Oklahoma cities. They suggest that certain administrative system characteristics, fringe benefits, and evaluation policies cluster independently of each other. For example, by knowing that a city has performance evaluation policies, we know that it is likely to have other examination or evaluation procedures, but the characteristics of its fringe benefits would not be predictable from this dimension. In addition, the existence of a merit pay raise is independent of most other characteristics, i. e., it tends to be more randomly dispersed among Oklahoma cities with regard to other personnel

${ }^{7}$ Mixed signs for the correlation coefficients are a function of the loading patterns displayed in Table 5; especially note factor II and IV.

characteristics (except for probationary periods). Several of these policy 
characteristics are also positively related to city size and budget, especially the evaluation/professional dimension.

\section{Sets of Training Needs, Personnel Policies and City Characteristics}

While the above discussion documents the existence of independent sets of personnel policies among the cities under study, policy makers must also have some feel for the coexistence of sets of training needs. While we have suggested a relatively weak relationship between personnel policies and overall training interest, a variety of effects can be hidden in the general training interest concept and the accompanying score for each city. In order to uncover basic dimensions of needs, we followed a procedure similar to that applied to personnel policies. The levels of interest in each of 21 training areas were intercorrelated with one another and that intercorrelation matrix was examined for clustered relationships through factor analysis. The results of this effort appear in Table 7.

Table 7

$$
\begin{gathered}
\text { Factor Analysis (Varimax)* of Employee Training Needs } \\
\text { in Oklahoma Cities }
\end{gathered}
$$

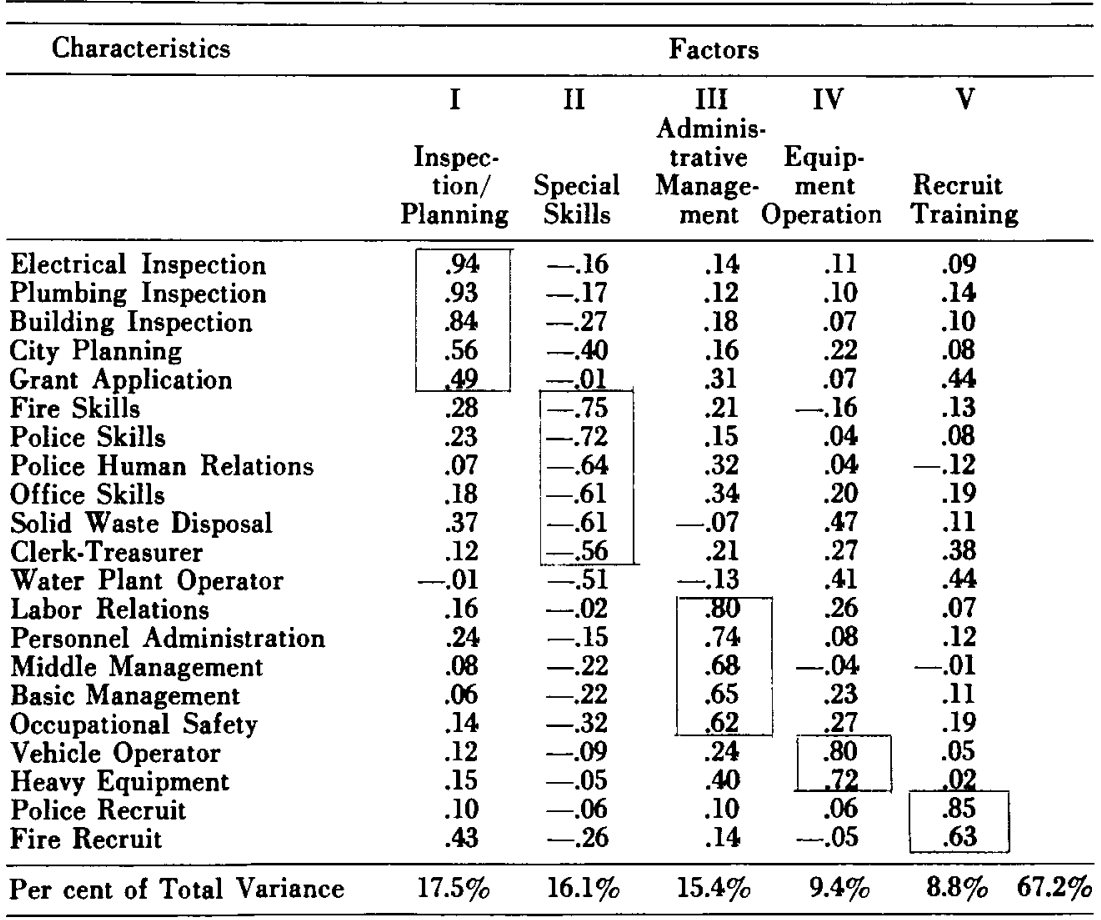

*Varimax rotation of principal components solution; Kaiser's criterion 
The factor analysis suggests five underlying training interest dimensions among the 21 items, with those five factors accounting for $67 \%$ of the total variation in the intercorrelation matrix. It also supports the notion that training needs exist in clusters relatively independent of one another. That is, if one city has greater interest in training in one set of items making up a factor, it is not likely to have need for those in some other set. It is therefore undesirable from a policy perspective to treat all cities as if they had uniform or general training interests - instead, cities should become a focal point for training on the basis of one primary set of needs.

The basic factors which emerge are both empirically and intuitively meaningful. The first is an interrelated set of inspection and planning needs also characterized by interest in training in grant application skills. The second dimension is composed of specialized skill needs in the areas of police, fire, office, financial, and water and waste training. Thirdly, an administrative management dimension appears, characterized by interest in labor relations, personnel administration, and basic and middle management training. Also related to the management function are skills associated with occupational health and safety. The two remaining factors include equipment operation and recruit (fire and police) training needs.

Since city personnel characteristics and training needs have now been reduced to a few basic and internally independent dimensions, it is possible to summarize effects with considerable ease. Table 8 presents the correlations between the training need factor scores and the personnel policy factor scores, plus the overall relationship between need areas and city characteristics. While the general interest in training index was weakly related to city characteristics, specific patterns now emerge. This is par-

Table 8

Correlations Between City Characteristics/Personnel Policy Dimensions and Training Need Factors

\begin{tabular}{|c|c|c|c|c|c|c|}
\hline \multirow[t]{2}{*}{ Needs } & \multicolumn{6}{|c|}{ City Characteristics and Personnel Policies } \\
\hline & Population & Budget & $\begin{array}{c}\text { Evalua- } \\
\text { tion/ } \\
\text { Pro- } \\
\text { fessional }\end{array}$ & $\begin{array}{l}\text { Adminis. } \\
\text { trative/ } \\
\text { Personnel } \\
\text { System }\end{array}$ & $\begin{array}{c}\text { Fringe } \\
\text { Benefits }\end{array}$ & $\begin{array}{c}\text { No } \\
\text { Probation/ } \\
\text { Merit } \\
\text { Raise }\end{array}$ \\
\hline $\begin{array}{l}\text { Inspection/Planning } \\
\text { Special Skills } \\
\text { Administrative }\end{array}$ & $\begin{array}{r}-.03 \\
.17\end{array}$ & $\begin{array}{r}-.16 \\
.27\end{array}$ & $\begin{array}{l}.09 \\
.04\end{array}$ & $\begin{array}{r}.08 \\
-.11\end{array}$ & $\begin{array}{r}-.10 \\
-.17\end{array}$ & $\begin{array}{r}.12 \\
-.10\end{array}$ \\
\hline $\begin{array}{l}\text { Mangaement } \\
\text { Equipment Operator } \\
\text { Recruit Training }\end{array}$ & $\begin{array}{r}.60 \\
-.13 \\
-.02\end{array}$ & $\begin{array}{r}.38 \\
.09 \\
-.19\end{array}$ & $\begin{array}{r}-.43 \\
.06 \\
-.01\end{array}$ & $\begin{array}{r}.25 \\
-.23 \\
-.01\end{array}$ & $\begin{array}{r}-.35 \\
-.05 \\
.01\end{array}$ & $\begin{array}{r}.04 \\
-.01 \\
-.15\end{array}$ \\
\hline
\end{tabular}


ticularly true for the administrative management need dimension: higher population/budget cities have greater interest in training for administrative management skills $(r=.60$ and .38$)$. Weaker relationships exist between the other need areas and city characteristics. Indeed, slight correlations exist in the opposite direction: smaller cities have greater interest in operator (-.13) and special skills training (.17), and smaller budget cities have greater special skill needs $(.27) .^{8}$

Just as we could not conclude that all needs are related to city population and budget characteristics, Table 8 also suggests that all personnel policies are not associated with the entire set of 21 training interest areas. Rather, selective relationships exist between certain independent personnel areas and certain independent need areas. For example, the strongest relationships are found between the various personnel policies and the ad. ministrative management dimension. The other areas of training needs are generally unrelated to personnel policy characteristics. Indeed, knowledge of a city's size and/or budget is as good a predictor of areas of training needs as is knowledge of personnel characteristics. However, the relationship between administrative management needs and personnel policies suggests that only cities that are "better off" from any one of a number of personnel perspectives need or want administrative management training. If such skills are important to improving the level of services in city government, it is possible that we cannot "generate" a desire for them unless cities are already reasonably attuned to contemporary personnel practices.

\section{Conclusion}

This analysis has attempted to clarify the relationships between a municipality's intertst in employee training and its personnel practices, and at the same time to determine the extent to which these are related to certain city characteristics. A recent survey of 72 Oklahoma communities with a population of 2,500 or greater formed the basis for the study. A principal assumption underlying this effort has been that improved local public services may be related to advancements in training and personnel systems among localities, and that policy makers need a better grasp of the relationships between these important aspects of city government.

The findings suggest that cities can be differentiated with respect to overall interest in training, and definite preferences among cities for particular training activities can be identified. However, these general mani-

8These latter two coefficients are positive due to the pattern of factor loadings in Table 7, factor II. 
festations are not strongly associated with city size or budget. In addition, the analysis revealed that certain personnel practices existed together in cities, and that training needs co-occurred in relatively independent clusters. Most sets of personnel practices were fairly closely related to one particular training area - a group of administrative management needs. Large cities and those with bigger budgets were also likely to evidence greater interest in this same training area.

Certain policy implications seem to follow from this analysis. Despite recent stimuli from the Federal government, such as the Intergovern. mental Cooperation Act and the Intergovernmental Personnel Act, there are indications of a plateau in the spread of merit and associated principles as well as decreasing academic interest in the subject. ${ }^{9}$ The implications of such a trend are particularly noteworthy when we consider that a "cumulative inequality" process may be at work. Larger cities with more ample budgets have better developed personnel systems. These same cities are also more likely to show greater interest in sophisticated training needs. Thus, those most advanced cities are more attuned to the need of further improvements and vice versa. While it may not be possible to force feed local governments, policy makers at whatever governmental level need to be aware of this situation where it appears that the rich may get richer and the poor less so.

9See Rosaline Levenson, "The Merit Principle in Municipalities - Strengthened or Eroded?" 1 Personnel Administration/Public Personnel Review, (1972), pp. 46-50.

We invite contributions of 250 to 500 words to the

PUBLIC ADMINISTRATION FORUM 16 ENFORCEMENT OF EQUAL
OPPORTUNITY PROVISIONS IN
CONTRACT COMPLIANCE

Contributions to the discussion are invited. Please send papers to the Forum Editor.

Forum Editor: Ms. Mary Hayes Director, Department of Human Relations City of Kansas City, Missouri, 4th Floor, City Hall Kansas City, Missouri 64106

Deadline: June 1, 1974

This Forum will appear in the July 1974 issue 